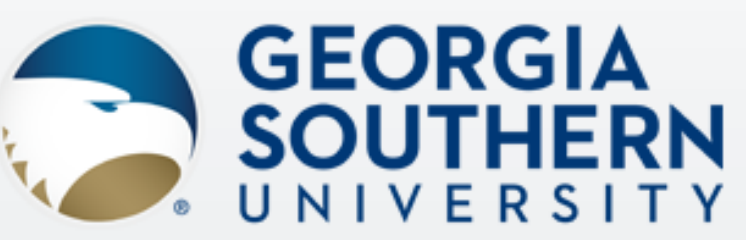

\title{
Noise and Vibration Issues of Wind
} Turbines and Their Impact - A Review Rudolf Saavedra \& Biswanath Samanta* Department of Mechanical Engineering *E-mail: bsamanta@georgiasouthern.edu 


\section{Presentation Overview}

$\square$ Introduction

$\square$ Background

$\square$ Human Ear, Sound, Weight Filters, Octave bands

$\square$ Noise

$\square$ Noise generation, Noise Type, Noise Propagation

$\square$ Environmental Concerns

$\square$ Human Health, Wild life

$\square$ Standards

$\square$ Conclusions 


\section{Introduction}

$\square$ There is a growing interest in wind power, both within the US and internationally, as a potential renewable source of energy.

$\square$ It is predicted that the overall power generation from wind will grow in the US to 35\% by 2050 (US Department of Energy, 2015). 


\section{Introduction}

$\square$ However, there are some issues, in harnessing the wind energy through use of wind turbines, that impede the wide spread utilization of wind power.

$\square$ The issues in wind turbines include

$\square$ environmental impact causing concern for both humans and wild life,

$\square$ noise and vibrations caused by operation, and

visual and aestheticimpacts 


\section{Background}

- Human Ear-

- perceive sound in a range of $20 \mathrm{~Hz}$ to $20 \mathrm{kHz}$

- audibility remaining below $20 \mathrm{~Hz}$ but losing the tonal sensation.

- Sound level - decibel

$-L \downarrow w=10 \log \downarrow 10(P / P \downarrow 0)$ : power

$-L \downarrow p=20 \log \downarrow 10(p / p \downarrow 0):$ pressure 


\section{Background}

Weighting filter:

$\square$ Sound measurement devices use weighting (denoted as $\mathrm{dBA}, \mathrm{dBB}$, $d B C, d B D, d B G, d B Z$ ) which accounts for the change in sensitivity in human ears at varying frequencies.

$\square \mathrm{A}(\mathrm{dBA})$ weighting corresponds approximately to the 40 phon equal loudness.

$\square$ dBA scale is most widely used .

Octave bands:

$\square$ Sounds can generate noise with distinct frequency components that can be presented using any frequency band, one-third $\left(1 / 3^{\text {rd }}\right)$ octave frequency band being the most common.

The audio spectrum from $20 \mathrm{~Hz}$ to $20 \mathrm{KHz}$ can be divided up into $311 / 3$ octave bands 


\section{Typical Noise Levels}

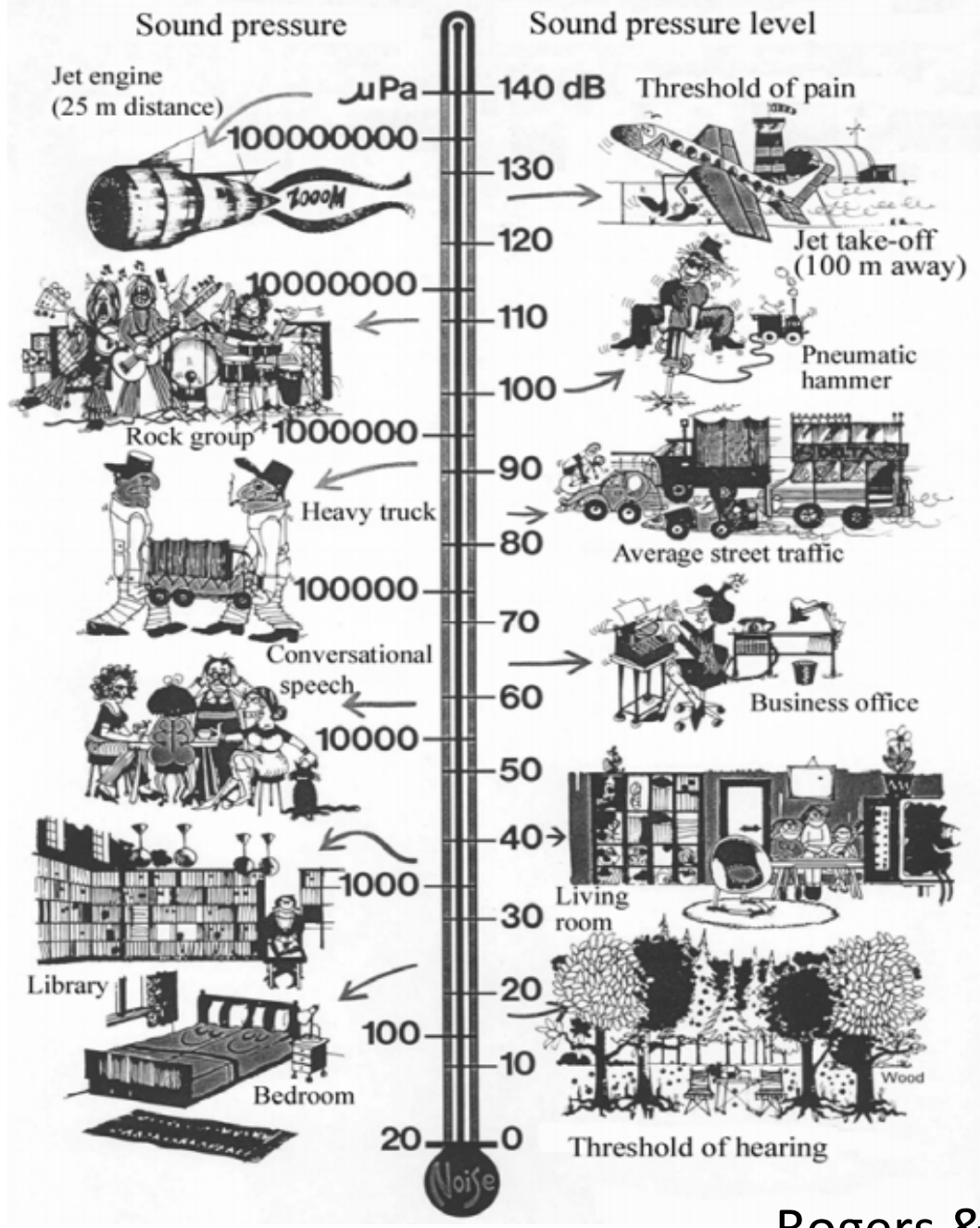

Rogers \& Manwell, 2002 


\section{Noise}

$\square$ Noise by definition is any unwanted sound and a large concern for wind turbines.

$\square$ The noise is generated from two aspects; the aerodynamic forces of the wind on the turbine blades, and the mechanical operation of the turbine.

$\square$ Modern gearboxes are now very quiet and therefore the dominant noise sources are located on the blade. 


\section{Noise Generation}

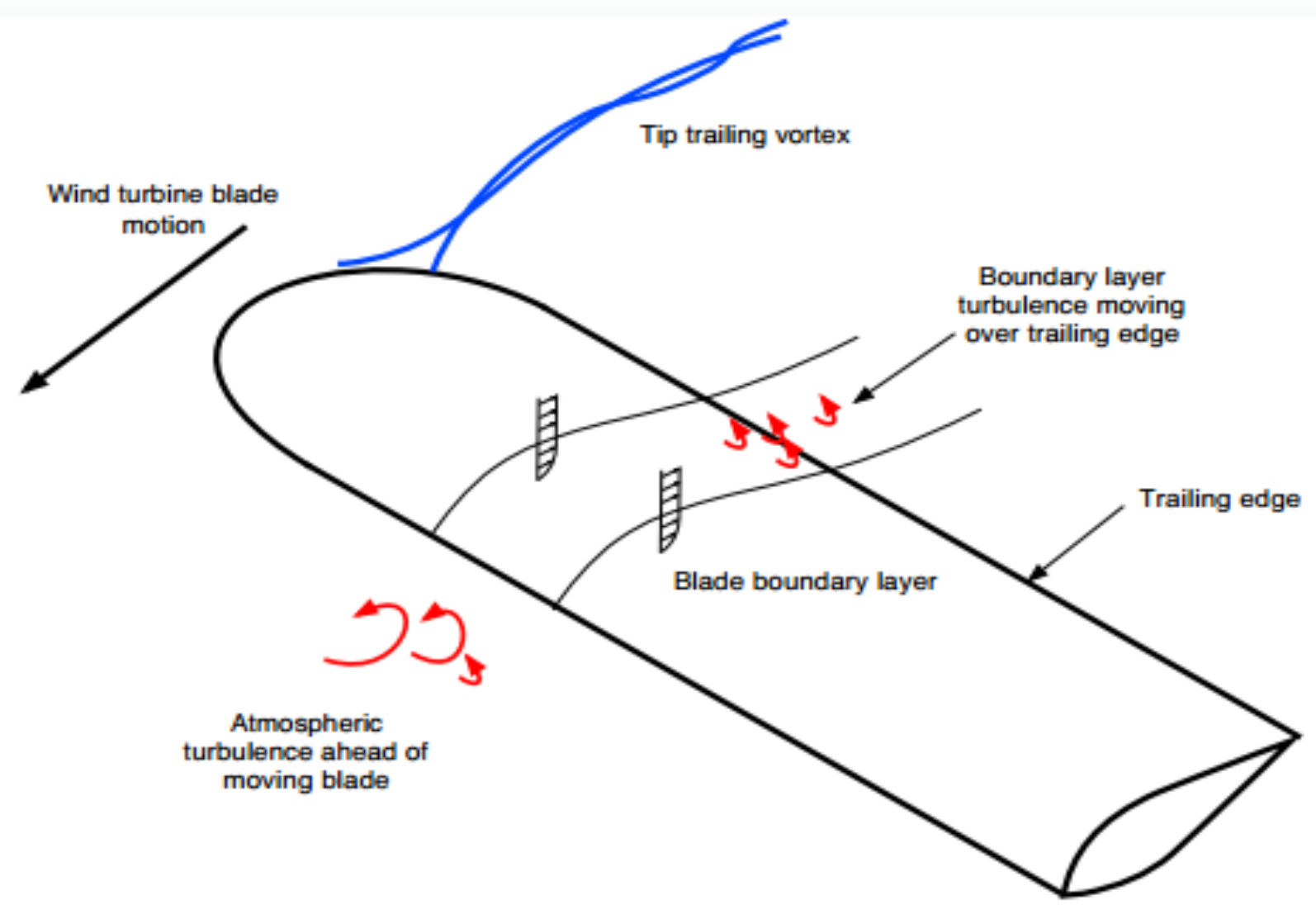

Figure 1 The flow over a wind turbine blade tip. (Doolan, Moreau, \& Brooks, 2012) 


\section{Noise Types}

Noise produced can be broken down into separate categories.

$\square$ Tonal - noise at discrete frequencies. It is caused by turbine components such as meshing gears, non-aerodynamic instabilities interacting with a rotor blade surface, or unstable flows over holes or slits or a blunt trailing edge (Rogers \& Manwell, 2002).

$\square$ Broadband - continuous distribution of sound pressure with frequencies above $10 \mathrm{~Hz}$. Broadband noise is caused by interaction of blades with atmospheric turbulence.

$\square$ Low Frequency noise - noise in the range of $20 \mathrm{~Hz}$ to $100 \mathrm{~Hz}$.

$\square$ Infrasound - noise below the $20 \mathrm{~Hz}$ range.

$\square$ Impulsive - short acoustic impulses or thumping sounds that vary in amplitude with time. Impulsive noise is caused by interaction of blades with disturbed air flow around the tower of a downwind machine. 


\section{Amplitude Nodulation}

- Amplitude modulation (AM) of aerodynamic noise from wind turbines is a phenomenon that occurs when broadband noise is modulated (slowly changing the amplitude with time).

$\square$ It arises when the blades of the rotor pass through different zones or directions of wind. The "swishing" or "thumping" sounds that can be heard near wind farms is a product of amplitude modulation.

$\square$ This is considered to be the most annoying aspect of wind turbine noise for residents that live near these farms (Davidsen, 2009).

$\square$ The causes of amplitude modulation are not fully understood and it cannot be fully predicted at the current state of art (Larsson \& Ohlund, 2014). 


\section{Environmental Concerns}

$\square$ Impact on Human Health

$\square$ Wind Turbine Design and Infrastructure

$\square$ Wind Turbine Noise

$\square$ Impact on Wild life 


\section{Impact on Human Health}

Wind Turbine Design and Infrastructure

$\square$ The nature of the design of a wind turbine and its operation cause a rhythmic flicker of light and shadow.

$\square$ Studies suggest that flicker from turbines that interrupt or reflect sunlight at frequencies greater than $3 \mathrm{~Hz}$ pose a potential risk of inducing photosensitive seizures.

$\square$ Three blade turbines must be limited to a maximum speed of rotation of $60 \mathrm{rpm}$ to maintain below $3 \mathrm{~Hz}$ (Knopper \& Ollson, Health Effects and Wind Turbines: A Review of the Literature, 2011).

$\square$ The flicker frequency of wind turbines is generally at $1 \mathrm{~Hz}$, which is too low for epileptic response (Davidsen, 2009) (McCunney, et al., 2014). 


\section{Wind Turbine Design and Infrastructure}

$\square$ Wind turbines also pose the risk of structural failure.

$\square$ This is an issue for any object with mechanical operation. The most common point of failure arises from faults in the drivetrain led by the gearbox.

$\square$ This can be predicted and prevented by utilizing vibration modeling (Zhang, 2009) (Zhang, Verma, \& Kusiak, 2012). 


\section{Wind Turbine Noise}

WWind turbine operation creates varying levels of noise dependent on many factors, which has potential to be of concern for human health (McMurty, 2010) (McMurtry \& Krogh, 2014).

DThe topic of noise being harmful to humans is controversial with studies showing results for both sides and no definitive answer to date. 


\section{Wind Turbine Noise}

The effects of noise on people can be classified into three general categories (Rogers \& Manwell, 2002).

$\square$ Subjective effects including annoyance, nuisance, dissatisfaction.

$\square$ Interference with activities such as sleep, speech, and learning.

$\square$ Physiological effects such as anxiety, tinnitus, or hearing loss. 


\section{Wind Turbine Noise}

$\square$ Various studies state that when properly sited, wind turbines are not related to adverse health effects (Knopper L. D., et al., 2014) (Colby, et al., 2009) (Knopper \& Ollson, 2011).

$\square$ Experts concluded that the sounds from wind turbines are not unique and there is no evidence to believe that the sounds from wind turbines could plausibly have direct adverse health consequences (Colby, et al., 2009) (McCunney, et al., 2014) (Dai et al. 2015). 


\section{Low Frequency Noise}

The potential health effects from low frequency noise include:

$\square$ noise-induced hearing impairment;

$\square$ interference with speech communication;

$\square$ disturbance of rest and sleep; psycho physiological, mental health, and performance ability;

$\square$ effects on residential behavior and annoyance; interference with intended activities;

$\square$ Vibro-Acoustic Disease (VAD),

$\square$ Wind Turbine Syndrome (Davidsen, 2009) (Knopper et al., 2014). 


\section{Low Frequency Noise}

VAD is a collection of symptoms that are claimed to be caused by low frequency noise (Davidsen, 2009).

- Studies have shown that animals and humans can be affected by intense levels of low frequency noise and newer studies suggest that lower levels of low frequency noise can affect the human body (Davidsen, 2009).

- Hearing loss caused by low frequency noise has been reported in both humans and animals.

This occurred with sound pressure levels above $100 \mathrm{~dB}$.

- Adequately designed wind turbines will never produce this much sound pressure, thus this issue is not a concern (Davidsen, 2009) (McCunney, et al., 2014). 


\section{Infrasound}

$\square$ Infrasound is not unique to wind turbines and has been associated with learning, sleep and cognitive disruptions as well as stress and anxiety (Knopper \& Ollson, 2011).

$\square$ Infrasound has been demonstrated to cause physiological changes in humans at levels of $110 \mathrm{~dB}$, but it remains unknown if exposure to infrasound from wind turbines does cause adverse health effects or if these potential health effects are the results of psychological mechanisms (Schmidt \& Klokker, 2014).

$\square$ Another study states that infrasound near wind turbines does not exceed audibility thresholds and does not present unique health risks (McCunney, et al., 2014). 


\section{Impact on Wild Life}

$\square$ Animals are also affected by wind turbines which are mainly birds and bats.

$\square$ The installed turbines disrupt the natural flight path of the avian population and will indeed kill any animal that approaches too closely to the blades.

$\square$ Studies indicated that low fatality rates exist at most wind energy developments with the exception of some facilities in parts of California (National Wind Coordinating Collaborative, 2010). 


\section{Steps for Reducing Wind Turbine Noise}

Current technology aims at reducing the noise emitted from wind turbines. These include but are not limited to:

$\square$ gearbox design,

$\square$ upwind rotor wind turbine design,

$\square$ limiting the speed of the blade tips, and

$\square$ turbine blade design.

$\square$ The technology to reduce noise and vibration from improved design of wind turbines are subjects of active research (Zhang, Verma, \& Kusiak, 2012).

$\square$ Vibrations of a wind turbine have a negative impact on its performance (Zhang, 2009). Data collected can be utilized in developing optimization models for improved performance of wind turbines.

$\square$ Premature component failures are a common occurrence in wind turbines. The majority of these failures are caused by faults in the drivetrain, led by the main gearbox.

$\square$ This fault can be detected by utilizing vibration analysis (NREL, 2012) (Zhang, Verma, \& Kusiak 2012). 


\section{Standards}

In order to accurately assess the noise produced by wind turbines, measurement of the data is necessary.

Instrumentation for this purpose include microphones, digital recorders, signal analyzers, calibrators, pressure sensors, temperature sensors, and a data acquisition system, as well as other optional instruments.

It is necessary to measure raw data, the overall sound pressure level, and one- third octave spectra. It is also necessary to measure the power, wind speed, wind direction, rotor speed (optional), pressure, and temperature.

The IEC Acoustic Standard IEC 61400-11 (Huskey, 2011) states the desired measurements and averages. 


\section{Standards}

In order to accurately assess the noise produced by wind turbines, measurement of the data is necessary.

Instrumentation for this purpose include microphones, digital recorders, signal analyzers, calibrators, pressure sensors, temperature sensors, and a data acquisition system, as well as other optional instruments.

It is necessary to measure raw data, the overall sound pressure level, and one- third octave spectra. It is also necessary to measure the power, wind speed, wind direction, rotor speed (optional), pressure, and temperature.

The IEC Acoustic Standard IEC 61400-11 (Huskey, 2011) states the desired measurements and averages. 


\section{Standards}

$\square$ AWEA standards for small wind turbines require that sound levels shall be measured and reported in accordance with the latest edition of IEC 61400-11 ed.2, incorporating the additional guidance provided.

$\square$ The averaging period is recommended to be 10-second instead of 1minute, with direct measurement of wind speed directly instead of deriving it through power.

$\square$ The method of bins shall be used to determine the sound pressure levels at integer wind speeds, covering as wide a wind speed range as possible, as long as the wind screen remains effective.

$\square$ It is required to provide any obvious changes in sound at high wind speeds where over-speed protection becomes active (like furling or pitching).

$\square$ It also states that tonality analysis is not required, but the presence of prominent tones shall be observed and reported. 


\section{Conclusion}

$\square$ The paper reviews :

$\square$ the current literature on the issues of noise and vibration of wind turbines and their impact on human health and wild life,

$\square$ the current status of technology and future developments to mitigate the health and environmental impacts of wind turbine noise and vibration,

$\square$ the current standards on measurement of acoustic noise of wind turbines and data analysis.

More research is needed to establish a connection between wind turbine noise and potential effects on human health.

$\square$ However, it is very important to take into account the perceived concerns of community in siting decisions of wind turbines for wider acceptance of wind as an important renewable energy source. 


\section{References}

- Dai, K. et al (2015). Environmental Issues Associated with Wind Energy - A Review, Renewable Energy, 75, 911-921.

- Hessler, D. M., and Hessler, G. F. (2011) Recommended Noise Level Design Goals and Limits at Residential Receptors for Wind Turbine Developments in the United States, Noise Control Engineering, 59:1:94-104.

- Huskey, A. (2011). IEC Acoustic Standard IEC 61400-11. NREL.

- Knopper, L. D., Ollson, C., McCallum, L. C., Whitefield Aslund, M. L., Berger, R. G., Souweine, K., \& McDaniel, M. (2014). Wind Turbines and Human Health. Frontiers in Public Health, 1-20.

- McCunney, R. J., Mundt, K. A., Colby, W. D., Dobie, R., Kaliski, K., \& Blais, M. (2014). Wind Turbines and Health: A Critical Review of the Scientific Literature. Journal of Occupational and Environmental Medicine 56(11), 108-130.

- McMurtry, R. (2010). A Primer on Adverse Health Effects and Industrial Wind Turbines, Society for Wind Vigilance.

- McMurtry, R., \& Krogh, C. M. E. (2014). Diagnostic Criteria for Adverse Health Effects in the Environs of Wind Turbines. Journal of Royal Society of Medicine 5(10),1-5.

- Rogers, A. L., \& Manwell, J. F. (2002). Wind Turbine Noise Issues. Amherst: University of Massachusetts at Amherst.

- Schmidt, J. H. and Klokker, M. (2014). Health Effects Related to Wind Turbine Noise Exposure: A Systematic Review, PLoS ONE 9(12): e114183.

- US Department of Energy. (2015). Wind Vision: A New Era for Wind Power in the United States. US Department of Energy.

- Zhang, Z., Verma, A., \& Kusiak, A. (2012). Fault Analysis and Condition Monitoring of the Wind Turbine Gearbox. IEEE Transactions of Energy Conversion, 526-535. 
Thank You 